\title{
Comprehensive Application of Different Methods of Observation Provides New Insight into Flower Bud Differentiation of Double-flowered Paeonia lactiflora 'Dafugui'
}

\author{
Jianjun Zhang and Wei Zhu \\ College of Landscape Architecture, Beijing Forestry University, Beijing \\ 100083, P.R. China; Beijing Key Laboratory of Ornamental Plants \\ Germplasm Innovation and Molecular Breeding; and National Engineering \\ Research Center for Floriculture, Beijing 100083, P.R. China \\ Jaime A. Teixeira da Silva \\ Independent, P.O. Box 7, Miki-cho post office, Ikenobe 3011-2, Kagawa-ken, \\ 761-0799, Japan
}

\section{Yongming Fan and Xiaonan $\mathbf{Y u}^{\mathbf{1}}$ \\ College of Landscape Architecture, Beijing Forestry University, Beijing 100083, P.R. China; Beijing Key Laboratory of Ornamental Plants Germplasm Innovation and Molecular Breeding; and National Engineering Research Center for Floriculture, Beijing 100083, P.R. China}

Additional index words. bud development, flower type, herbaceous peony, observation methods of bud differentiation

\begin{abstract}
The analysis of herbaceous peony (Paeonia lactiflora Pall.) floral bud initiation and differentiation from autumn to early spring is important because flower formation is strictly correlated with flowering in late spring. A clear understanding of peony flower development would allow management practices to be optimized for stable annual production and supply of cut flowers. The aim of this research was to study the timesensitive characteristics underlying flower development in peony cultivar 'Dafugui'. Flower bud differentiation was assessed by paraffin and hand-made slices, as well as stereomicroscopy. Both methods have strengths and weaknesses. Our observations are not entirely consistent with those of previous studies. Flower bud differentiation in 'Dafugui', which starts from late September to mid-April of the following year, is divided into differentiation of the lower parts (separate differentiation periods for the bracts, sepals, petals, stamens, and pistillodes) and upper parts (separate differentiation periods for the petals, stamens, and pistil), and is closely related to annual changes in ambient temperature. Differentiation of lower flower buds takes place before winter dormancy, whereas that of upper parts starts early in the following spring, and finally forms a double-flowered type. The three methods used in this article can be used to study $P$. lactiflora flower bud differentiation and can contribute to an understanding of this process in the future.
\end{abstract}

Herbaceous peony (Paeonia lactiflora Pall., Paeoniaceae) is a popular ornamental plant that grows well in temperate regions, blooming from May to July in the Northern hemisphere (Zhao et al., 2012). P. lactiflora has a long-standing reputation as the "garden queen" in many Western countries, whereas

\footnotetext{
Received for publication 22 May 2018. Accepted for publication 16 Nov. 2018.

This work was financially supported by the Co-building Graduate Training and Development Program of the Beijing Municipal Commission of Education (BLCXY201614) and the National Natural Science Foundation of China (31400591).

${ }^{1}$ Corresponding author. E-mail: yuxiaonan626@ 126.com.
}

in China it is a symbol of prosperity and wealth, and has enjoyed a good reputation as a famous traditional flower for more than 3000 years (Kamenetsky and Dole, 2012; Qin, 2004). P. lactiflora has a large germplasm, with more than 600 cultivars worldwide whose flower-related characteristics vary widely among cultivars (Zhao et al., 2014). Most varieties are highly valued commodities in the horticultural industry.

Flower bud development is a highly complex process that is characterized by two distinct physiological phases: floral initiation and floral bud development (Fan et al., 2015; Koutinas et al., 2010). The formation of peony flower buds and their related developmental events are controlled by multi- ple genetic factors (Ge et al., 2014), and these are influenced by seasonal changes in daylength and temperature (Zhang et al., 2015). The differentiation of floral buds during autumn until the following spring must go through a period of bud dormancy in cold winter, indicating that plants cease meristem activity and are insensitive to growthpromoting signals for some time before they can resume growth (Rohde and Bhalerao, 2007). Temperature is strictly correlated with flowering in the spring, as well as the geographic distribution of plants (Hall et al., 2007; Walton et al., 2007). The floral transition of plants and other developmental processes depend on changes in photoperiod and low temperature (Park et al., 2015; Zhao et al., 2012). Prolonged chilling before forcing at warm temperatures promotes the release of dormancy, but it is commonly accepted that low temperature is sensed by the shoot apical meristem only after the bud reaches a certain stage of development (Barzilay et al., 2002). Thus, the synchronization of environmental conditions and bud differentiation is critical for the flowering time of plants, and is of great importance to sustainable cut flower or potted plant production (Koutinas et al., 2010).

Over the past few decades, great attention has been paid to the study of peony flower types, which can be classified into six types, including single, Japanese, anemone, semidouble, bomb, and double types, in Western countries (Kamenetsky and Dole, 2012). The process of flower bud differentiation of some of these types of flowers has also been studied. Flower bud differentiation of single-type $P$. lactiflora 'Fenyunu' was investigated by stereomicroscopy (Wang and Zhang, 1991) and also under an optical microscope using paraffin sections (He et al., 2014). Anemone (P. lactiflora 'Yulinghong') and semidouble ( $P$. lactiflora 'Zijinlong') types were observed by cryosections under an optical microscope (He et al., 2007). Ai (2016) investigated the differentiation of anemone-type $P$. lactiflora 'Liantai' flowers by using paraffin sections under an optical microscope. These studies showed that flower bud differentiation was basically similar among different cultivars, and can be divided into several successive stages of differentiation: formation of leaf, bract, sepal, petal, stamen, and pistil primordia, whereas the flowers are organized into concentric whorls of bracts, sepals, petals, stamens and carpels (He et al., 2007; Huang et al., 2009; Wang and Zhang, 1991). Compared with the single type, other flower types often arise when some or all of the stamens in a flower develop various types of abnormal petals after bud dormancy release in early spring (Ai, 2016; He et al., 2014).

In China, proliferated peonies are often called "Taige" by horticulturists, indicating that a flower with many more than the normal number of petals often contains a flower within a flower, which can be categorized as double-flowered in the Western classification system (Ai, 2016; Lian et al., 2004; 
Meyerowitz et al., 1989; Qin and Li, 1990). This flower shape is common in many ornamental plants, and a large number of doubleflowered varieties are found in Camellia japonica (Zhang, 2006), Nelumbo nucifera (Jiang et al., 2009), Amygdalus persica (Wang and Zhang, 2010), Osmanthus fragrans (Zhu et al., 2012), and other plants. The double type of peony has the most popular varieties in the commercial cut flower market as they tend to have a longer postharvest shelf life (Cheng et al., 2009; Lian et al., 2004; Meyerowitz et al., 1989). However, there are fewer studies on flower bud differentiation of double-flowered peony than of other kinds of flower types. Barzilay et al. (2002) observed flower bud development of double-flowered P. lactiflora 'Sarah Bernhardt' by scanning electron microscopy, but focused mainly on the life cycle and morphogenesis of the floral shoot and failed to fully understand the complete process of bud differentiation, which is crucial for understanding the cause of flower type formation, and also the basis for molecular genetic research. Moreover, the description and classification of doubleflowered or other types are based primarily on morphological structures of flowers during the blooming period, but do not include bud differentiation. Until recently, such studies in herbaceous peony did not receive much attention from scientists because of the complicated structure of flower buds of double-flowered types and the lack of rapid and accurate methods to assess flower bud differentiation.

The objectives of this research were to study flower bud differentiation and the developmental stages of a double-flowered herbaceous peony cultivar (Paeonia lactiflora 'Dafugui', a traditional and popular variety with a long history of cultivation and applications, including use in city landscaping in northern China), and to find effective methods to assess $P$. lactiflora flower bud differentiation.

\section{Materials and Methods}

\section{Plant materials}

Four-year-old P. lactiflora 'Dafugui' plants were used (Fig. 1). They were planted in the research field of the Germplasm Resources Nursery of the National Engineering Research Center for Floriculture (long. $116^{\circ} 39^{\prime} \mathrm{E}$, lat. $40^{\circ} 17^{\prime} \mathrm{N}$; Beijing, China). The daily minimum and maximum temperatures in the experimental area are presented in Fig. 2.

\section{Methods}

Flower structure observation and analysis. In mid-May 2016 and mid-May 2017, terminal flowers on the floral shoot were randomly selected. Three biological replicates were collected from three individuals, and each biological replicate contained three flowers. Flower organs were manually dissected by hand from all flowers and ordered from external to internal parts. Samples were photographed with a digital camera
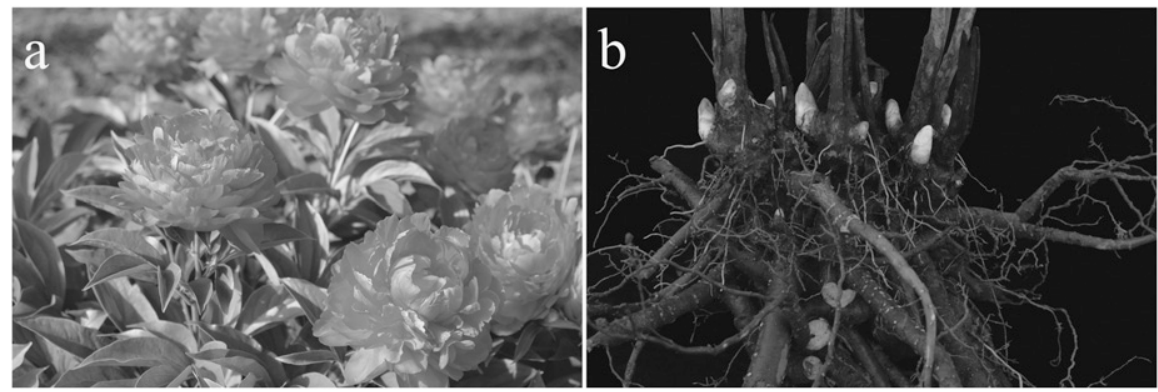

Fig. 1. Paeonia lactiflora 'Dafugui'. (a) Flower in full bloom; (b) underground buds, crowns and storage roots. Plants were maintained in the Germplasm Resources Nursery of the National Engineering Research Center for Floriculture $\left(116^{\circ} 39^{\prime} \mathrm{E}, 40^{\circ} 17^{\prime} \mathrm{N}\right.$; Beijing, China). Pictures were taken on 16 May 2017 (a) and on 15 Oct. 2016 (b).

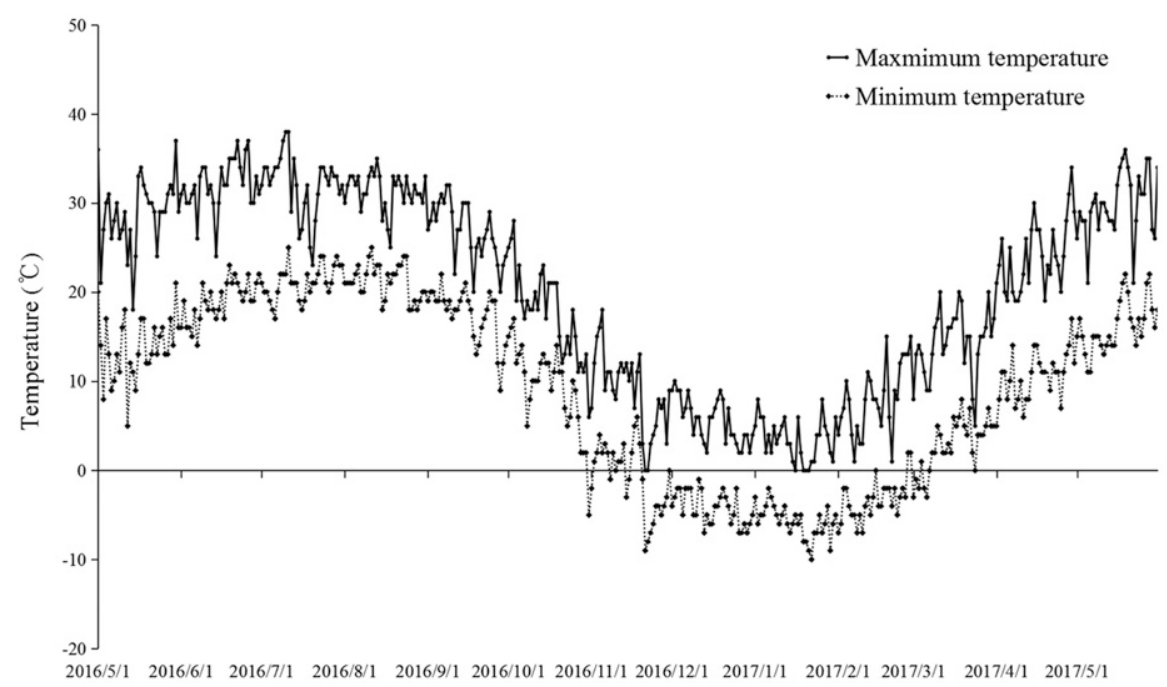

Date (Year/ Month/ Day)

Fig. 2. Maximum and minimum temperatures in experiment areas during the experiment period from Mar. 2016 to Mar. 2017. Data were provided by the Beijing meteorological station and by a meteorological observation station located in the sample plot $\left(116^{\circ} 39^{\prime} \mathrm{E}, 40^{\circ} 17^{\prime} \mathrm{N}\right.$; Beijing, China).

(18 mega-pixels; Canon EOS 1300D, Canon China, Beijing, China).

Observation of flower bud differentiation. From 15 July 2016 to 10 Apr. 2017, terminal buds at the top of the crown were collected from the base of each bud every 5 or $7 \mathrm{~d}$ except from 27 Nov. 2016 to 9 Mar. 2017 when they were collected every 3 weeks because sampling was difficult due to frozen soil. A total of 300 plants were sampled and three to four plants were randomly selected in each period. Five full and intact buds (vertical diameter $\times$ transverse diameter $\geq 1 \mathrm{~cm} \times 0.5 \mathrm{~cm})$ were collected from each plant.

The collected materials were washed with tap water and were randomized into three groups, each consisting of five buds. These were examined by three methods described in the following section.

Paraffin sections. The outer scales of buds were peeled off and buds were fixed in FAA solution ( $45 \%$ ethanol, $5 \%$ glacial acetic acid, $5 \%$ formalin, $45 \%$ water, $v / v$ ) for more than $24 \mathrm{~h}$ at $4{ }^{\circ} \mathrm{C}$. Samples were transferred to $50 \%$ ethanol for $2 \mathrm{~h}$ and then dehydrated in a $50 \%$, $70 \%$, and $95 \%$ ethanol series and twice in $100 \%$ ethanol at 1.5 -h intervals. The reagent was replaced by a solution of xylene and ethanol $(1: 1, \mathrm{v} / \mathrm{v})$ for $2 \mathrm{~h}$, followed by xylene, first for $2 \mathrm{~h}$, then in fresh xylene for $2 \mathrm{~h}$. All procedures were carried out at room temperature $\left(26 \pm 2{ }^{\circ} \mathrm{C}\right)$. Samples were decolorized in a mixture of xylene and paraffin $(1: 1, \mathrm{v} / \mathrm{v})$ for $8 \mathrm{~h}$, then four times in $100 \%$ paraffin at 4 -h intervals, all at $60{ }^{\circ} \mathrm{C}$. Samples were embedded in paraffin (Ai, 2016). Paraffin-embedded samples were sectioned to 10 - to $12-\mu \mathrm{m}$ thickness with a microtome (Leica RM2245; Leica Microsystems Nussloch GmbH, Nussloch, Germany), stained with a combination of safranin ( $4 \mathrm{~h})$ and fast green (15 s), and then observed under an optical microscope (Leica DFC550; Leica Microsystems GmbH, Wetzlar, Germany).

Hand-made sections. Fresh material was rinsed with water, then blotted dry on absorbent paper at room temperature for $10 \mathrm{~min}$. Buds at different developmental stages were cut into halves along the longitudinal axis and examined under a stereomicroscope (Leica DFC500).

Microscopic observations by stereomicroscopy. Buds were fixed in FAA for more than $24 \mathrm{~h}$ at room temperature. Bud 
samples prefixed in FAA were soaked in $50 \%$ ethanol for $\approx 2 \mathrm{~h}$ to remove FAA from the plant tissue, and then transferred to $50 \%$ then $70 \%$ ethanol for $1 \mathrm{~h}$ each. Samples were then stored in distilled water during dissection to prevent them from hardening, and were examined using a Leica DFC500 stereomicroscope.

\section{Reagents and consumables}

All reagents and consumables were purchased from Beijing Lanyi Chemical Products Co. Ltd. (Haidian District, Beijing, China).

\section{Measurements and analyses}

The timing of flower bud differentiation and the developmental stages of floral buds in 2016-17 were analyzed using the results of the three methods. In addition, the timing of natural dormancy release of underground buds ( $>50 \%$ of buds released from dormancy) and flowering time ( $>50 \%$ of flowers blossomed in mid-May 2017) were also analyzed.

\section{Results}

Observation of floral morphology. The flower of P. lactiflora 'Dafugui' (Fig. 1a), with an average diameter $11.47 \pm 1.44 \mathrm{~cm}$ and that developed from a renewed bud (Fig. 1b), can be divided into two (upper and lower) parts (Fig. 3). Their relative positions on the double flower were clear, and for observation purposes and to simplify descriptions, each part was regarded as a single flower from the viewpoint of structural composition, although they belong to different parts of the same flower.

Schematic diagram of floral structure of a fully opened flower. Figure 4 shows the floral organs of the lower part: bracts (green, leaflike, narrow and long, mostly five), sepals (green, leathery, broad, usually five), petals (generally five to six layers; outer petals are wide and flat; a few petals adjacent to the sepals are small and have green spots), numerous staminoides of varying shape, and pollenbearing stamens. There are five thick and large petals with green spots on the inside of stamens and this can be considered, from a morphological perspective, as a clean-cut separation between the lower and upper flowers. The morphological characteristics of petals and stamens of the upper part are similar to those of the lower part, but have morphologically normal carpels while no seeds are produced.

Observation of flower bud differentiation by paraffin slices. Differentiation of the lower part starts from the floral meristem, which is a small domed population of cells consisting of several cell layers, and usually when the meristem is flat it is still vegetative (Fig. 5a-b). At the end of September, the apical meristem becomes broader and more domed. Cells on the flanks of the floral meristem proliferate to first form the bract primordia (Fig. 5c), followed by the sepal primordia (Fig. 5d), petal primordia (Fig. 5e-g), stamen primordia (Fig. 5h-i), and pistillode primordia (Fig. $5 \mathrm{j}-\mathrm{k}$ ). However, the stamen and pistillode primordia show similar morphology,
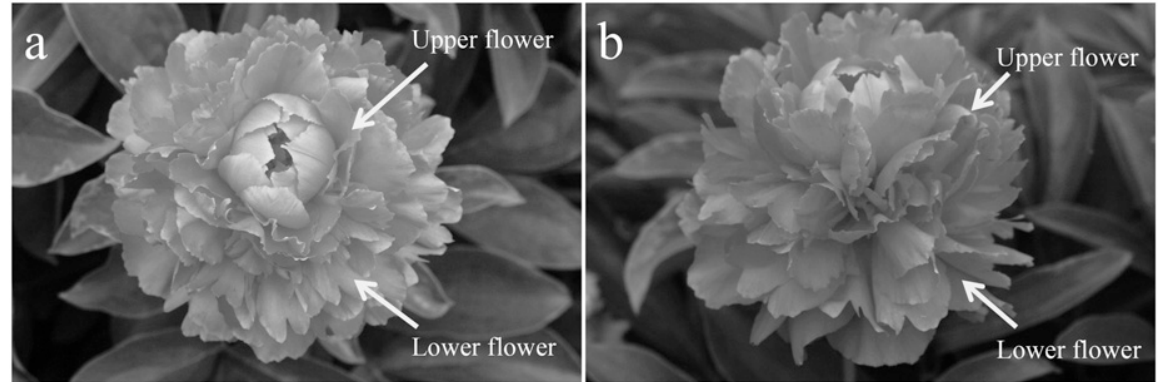

Fig. 3. Observation of structure and morphology of Paeonia lactiflora 'Dafugui' double flowers. (a) Overhead view of the flower; (b) side views of the flower. Pictures were taken on 16 May 2017.

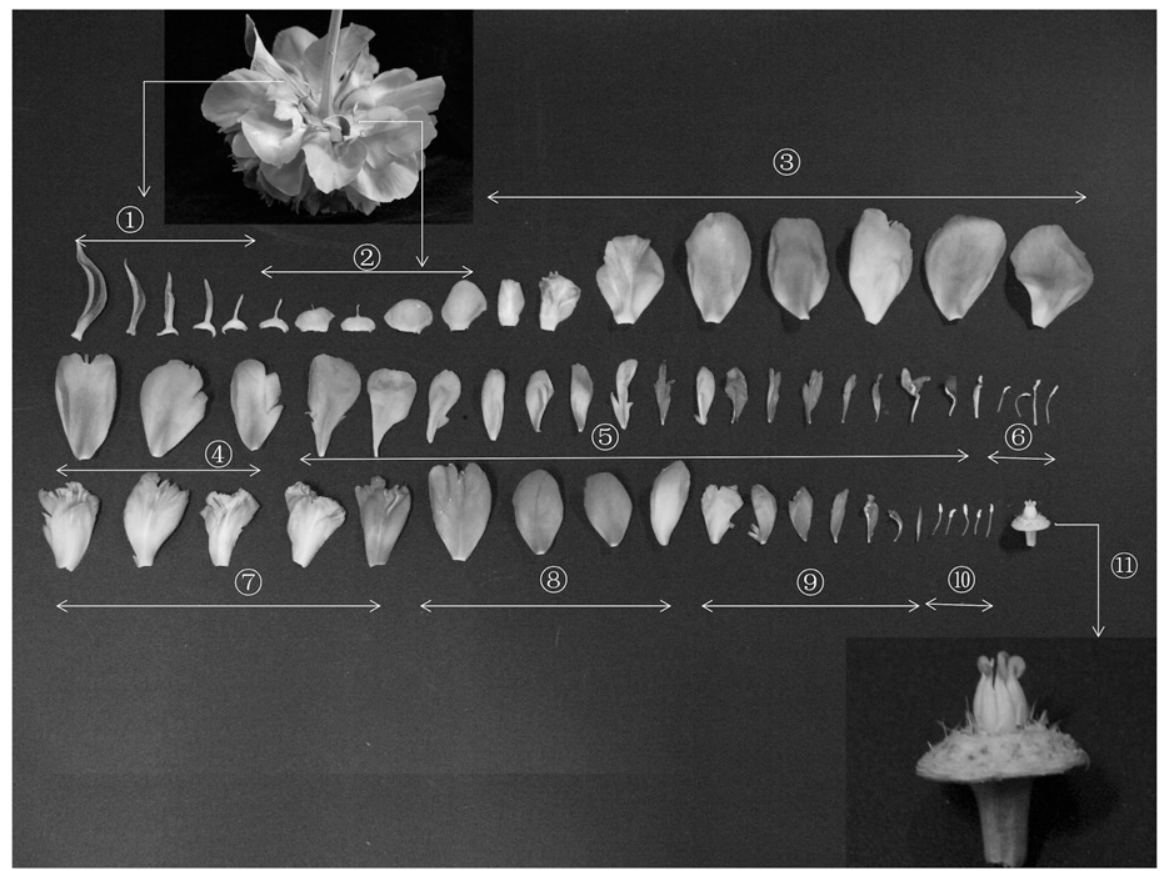

Fig. 4. Schematic diagram of floral structure decomposition of fully opened flower of Paeonia lactiflora 'Dafugui'. (1) Bracts of the lower flower; (2) sepals of the lower flower; (3) outer petals of the lower flower; (4) inner petals of the lower flower (generally, the inner petals are smaller than the outer petals); (5) staminodes; (6) stamens of the lower flower; (7) pistillodes of the lower flower; (8) petals of the upper flower; (9) staminodes of the upper flower; (10) stamens of the upper flower; (11) pistil of the upper flower. Pictures were taken on 16 May 2017.

and both were indistinguishable at an early developmental stage, as observed under an optical microscope. The generative meristem stopped development at the end of November and became dormant. At that time, the pistillode primordia were $\approx 0.2 \mathrm{~mm}$ wide and $0.15 \mathrm{~mm}$ high, and the two pistillodes were $0.25 \pm$ $0.02 \mathrm{~mm}$ apart (Fig. 5k).

Differentiation of the upper part differs from that of the lower part. The petal primordia of the upper part emerged on the inside of the pistillode primordia of the lower part at the beginning of March after dormancy release (Fig. 51-m). This was followed by the stamen primordia (Fig. 5n) and formation of the pistil primordia (Fig. 5o-p). While this occurred, the stamen and pistillode primordia of the lower part quickly enlarged, forming the staminode and pistillode, respectively.

Observation of flower bud differentiation by hand-held slices. Differentiation of the flower bud and morphological changes were examined under a stereomicroscope. Formation of the primordia of the lower and upper flower are displayed in Fig. 6. The morphological and color changes at different bud developmental stages can be observed intuitively. The growth rate of the lower flower pistillode was faster than that of the stamen in early spring, resulting in a distinct morphological difference between the two. The color of the petals and pistillodes of the lower part begins to change shortly after the petal of the upper part is formed and eventually turns red, while the bracts and sepals are green (Fig. 6j-o). The hierarchical arrangement within the floral bud were not analyzed nor are there any statistics.

Observation of flower bud differentiation by stereomicroscopy. Leaf or floral primordia are spirally arranged and unevenly distributed on the periphery of the meristem (Fig. 7a). Dissection of the terminal floral bud revealed a hierarchical arrangement with 


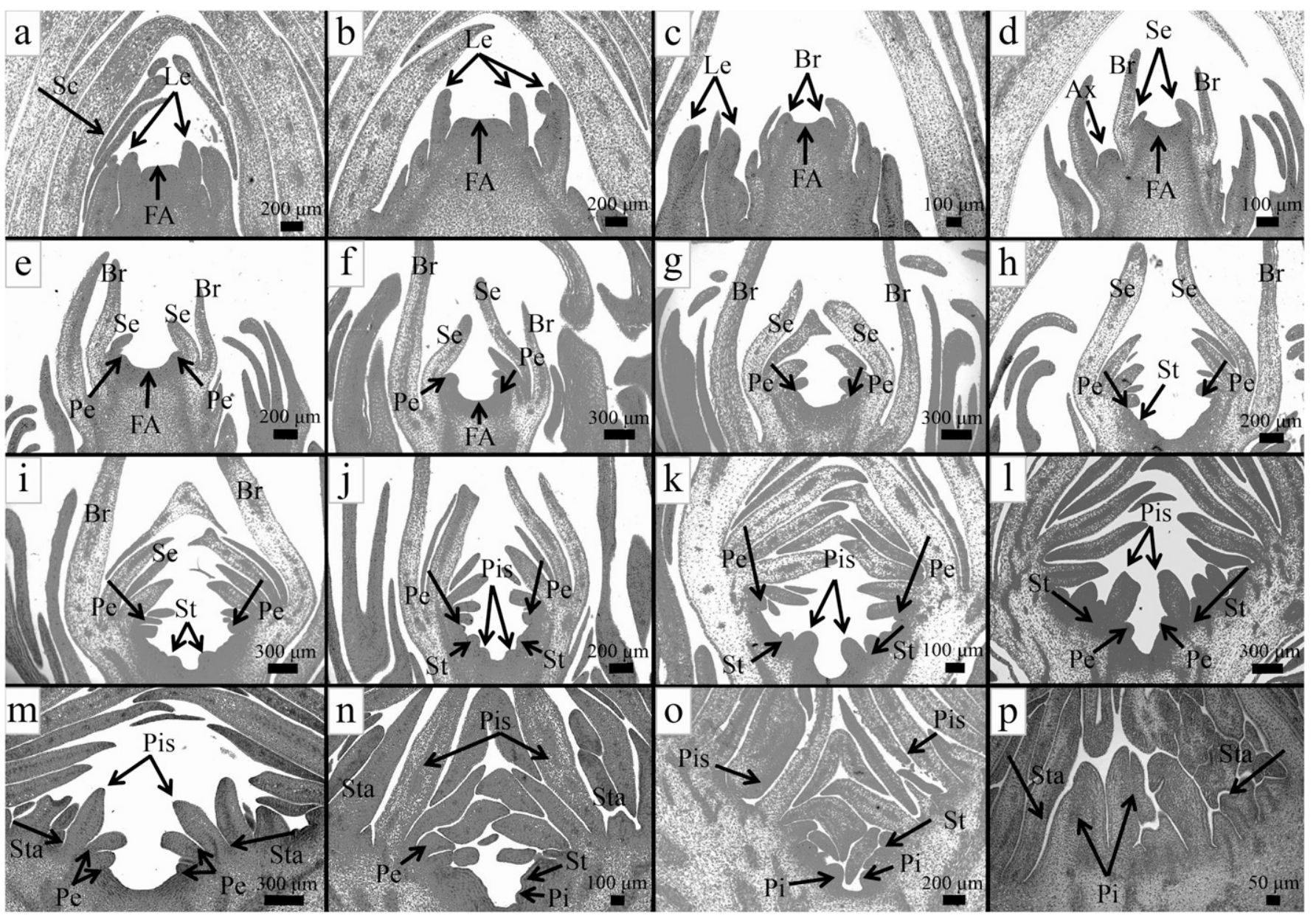

Fig. 5. Flower bud differentiation of Paeonia lactiflora 'Dafugui' flower observed by paraffin slices. (a-b) Leaf primordium differentiation period; (c) bract primordium differentiation period; (d) sepal primordium differentiation period; (e-g) petal primordium differentiation period of the lower flower; (h-i) stamen primordium differentiation period of the lower flower; $(j)$ pistillode primordium differentiation period of the lower flower (development of the generative meristem ceased at the end of November and became dormant until early Mar. 2017); (k) pistillode primordium differentiation period of the lower flower; (l-m) petal primordium differentiation period of the upper flower; (n) stamen primordium differentiation period of the upper flower; (o-p) pistil primordium differentiation period of the upper flower. Pictures were taken on 15 July 2016 (a), 5 Aug. 2016 (b), 26 Sept. 2016 (c), 1 Oct. 2016 (d), 6 Oct. 2016 (e), 11 Oct. 2016 (f), 16 Oct. 2016 (g), 21 Oct. 2016 (h), 3 Nov. 2016 (i), 27 Nov. 2016 (j), 3 Mar. 2017 (k), 10 Mar. 2017 (l), 15 Mar. 2017 (m), 25 Mar. 2017 (n), 6 Apr. 2017 (o), and 13 Apr. 2017 (p). FA = floral apex; Le = leaf primordium; Ax = axillary bud; $\mathrm{Br}=$ bract primordium; $\mathrm{Se}=$ sepal primordium; Pe = petal primordium; $\mathrm{St}=$ stamen primordium; $\mathrm{Sta}=$ staminode; $\mathrm{Pi}=$ pistil primordium; $\mathrm{Pis}=$ pistillode.

a single primordium at each node at an obtuse angle $\left(\approx 140^{\circ}\right)$ between primordia (Fig. $\left.7 \mathrm{~b}\right)$, and this state continued until differentiation of the initiated petal primordia. Generally, apical meristems were flat when the leaf primordia of the underground buds initiated, and there were $14 \pm 2$ leaf primordia when the buds proceeded to the generative stage. Initiation of the bracts indicates the end of the reproductive stage.

The flower bud differentiation process of the lower and upper parts is shown in Fig. 8 and Fig. 9, respectively. The apical meristem produced five leaf-like bracts, followed by five leaf-like sepals, both of which arose as a spiral on the periphery of the floral apex (Fig. 8a-c). Differentiation of the stamen primordia began at the core of the flower meristem and progressed centripetally (Fig. $8 \mathrm{~h}-\mathrm{i}$ ), whereas other floral parts progressed in turn from the edge to the center of the meristem concentrically. In late October, the apical meristem of the lower flower produced five pistillode primordia that initiated almost simultaneously (Fig. 8j). Differentiation ceased at the end of November. As temperatures rose in the following spring (Fig. 2), the pistillode primordia developed quickly (Fig. 9a-d), covering the apical meristems of the upper part (Fig. 9e-f). The apical meristems began to produce petal, stamen, and pistil primordia (Fig. 9d and g-h). The four to five pistils of the upper flower appeared almost at the same time on a circle of the apical meristem, which is consistent with the characteristics of the formation of pistillode primordia on the lower flower.

Flower development of peony 'Dafugui'. The times of flower bud differentiation and the developmental stages of the floral buds of $P$. lactiflora 'Dafugui' in Beijing between 2016 and 2017 are presented in Table 1. It took nearly 7 months for buds to complete differentiation. The differentiation period of the bract primordia of the lower flower started at the end of September, and within 2 months, the sepal, petal, stamen, and pistillode primordia had completed development, in this order. From the end of Nov. 2016 to the beginning of Mar. 2017, the underground buds became dormant as temperatures fell below zero and differentiation of the apical meristem slowed down. As temperatures rose at the beginning of Mar. 2017, differentiation of the petal primordia of the upper part restarted. By late Mar. 2017, the buds had emerged from the surface of the ground. During a rapid growth period of floral shoots, differentiation of the pistil primordia of the upper part started at the beginning of April, and the flowering period started on May 10, lasting $16 \mathrm{~d}$.

\section{Discussion}

Peony flowers are grouped into six primary types according to the shape of their petals, indicating that this classification is based primarily on flower morphological structures during the blooming period (Kamenetsky and Dole, 2012). However, these types are quite subjective, and in fact, there are also some differences between different varieties of the same flower type, especially for the varieties that classified as 

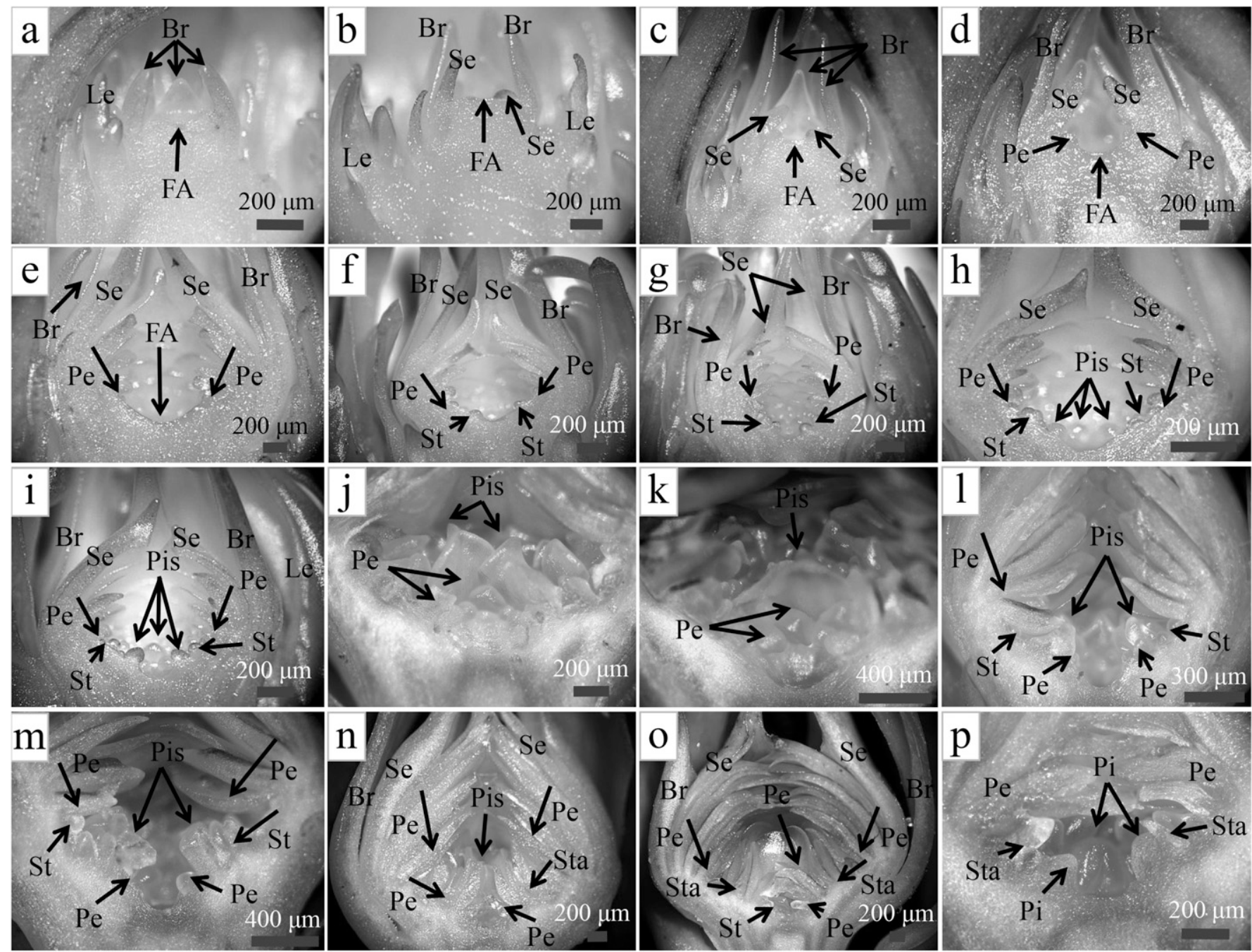

Fig. 6. Flower bud differentiation of Paeonia lactiflora 'Dafugui' flower observed by hand-held slices. (a) Bract primordium differentiation period; (b-c) sepal primordium differentiation period; $(\mathrm{d}-\mathrm{e})$ petal primordium differentiation period; $(\mathrm{f}-\mathrm{g})$ stamen primordium differentiation period of the lower flower; $(\mathrm{h}-\mathrm{j})$ pistillode primordium differentiation period of the lower flower; $(\mathrm{k}-\mathrm{n})$ petal primordium differentiation period of the upper flower; (o) stamen primordium differentiation period of the upper flower; (p) pistil primordium differentiation period of the upper flower. Pictures were taken on 26 Sept. 2016 (a), 1 Oct. 2016 (b-c), 6 Oct. 2016 (d), 16 Oct. 2016 (e), 21 Oct. 2016 (f), 3 Nov. 2016 (g), 27 Nov. 2016 (h), 4 Dec. 2016 (i), 15 Mar. 2017 (j), 3 Apr. 2017 (k-1), 8 Apr. 2017 $(\mathrm{m}-\mathrm{o})$, and 13 Apr. 2017 (p). FA = floral apex; Le = leaf primordium; $\mathrm{Ax}=$ axillary bud; $\mathrm{Br}=$ bract primordium; $\mathrm{Se}=$ sepal primordium; Pe = petal primordium; $\mathrm{St}=$ stamen primordium; $\mathrm{Sta}=$ staminode; $\mathrm{Pi}=$ pistil primordium; $\mathrm{Pis}=$ pistillode .
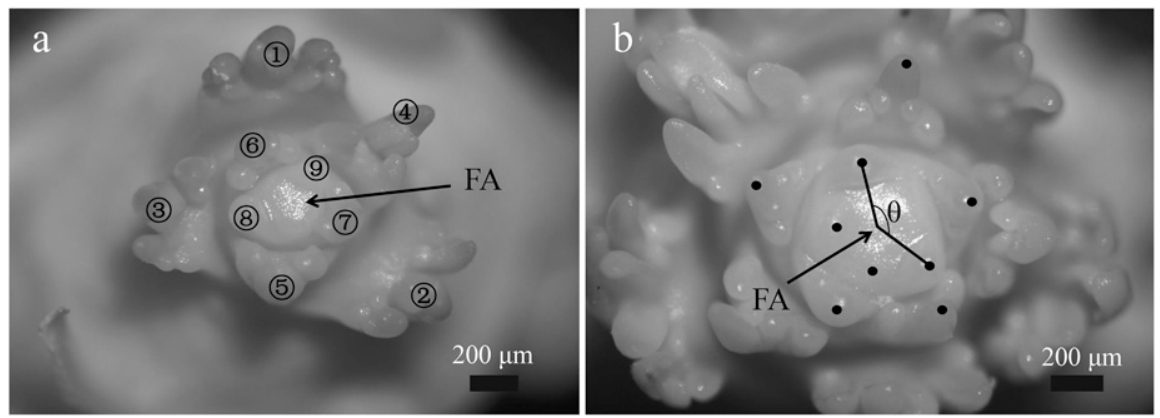

Fig. 7. Observation of primordium structure and morphology of the Paeonia lactiflora 'Dafugui' floral bud. (a) Distribution and arrangement of the leaf primordium (sampled on 25 July 2016); (b) diagrammatic illustration of the arrangement of two primordia that initiated successively (sampled on 15 Aug. 2016). 1-9 represent the first to ninth leaf primordia. The characters of the early pinnately compound leaf can be observed from 1 to 3 : the leaf first forms three branches, and then each branch forms three leaflets; (4) the leaf first forms three branches, and there are three leaflets on the middle branch, while one leaflet forms on both sides of the branch; (5-7) the leaf forms three branches; (8-9) growth into a single small protuberance from the edges of the floral apex. $F A=$ floral apex; $\theta$ represents the angle of divergence.

double type (Ai, 2016; Lian et al., 2004). The differentiation of peony floral buds is an important way to understand the formation of each flower type, and much work has been done in this field over the past 3 decades (Table 2). Overall, the vast majority of studies showed that bud differentiation of different cultivars, including single, anemone, and semidouble types, are basically the same, and includes differentiation periods of bract, sepal, petal, stamen, and pistil primordia. It is usually believed that flower bud differentiation can be completed within two seasons, that is, in the fall of the first year, when buds only proceed to the early morphology of the stamen or pistil primordia, while primordia reach maturity in the second spring, and usually this process is synchronized with the elongation of the stem. Herbaceous plants that conform to this characteristic include Anemone ranunculoides, Pulmonaria obscura, and Ranunculus cassubicus, although the degree of preformation of the pistils and stamens 


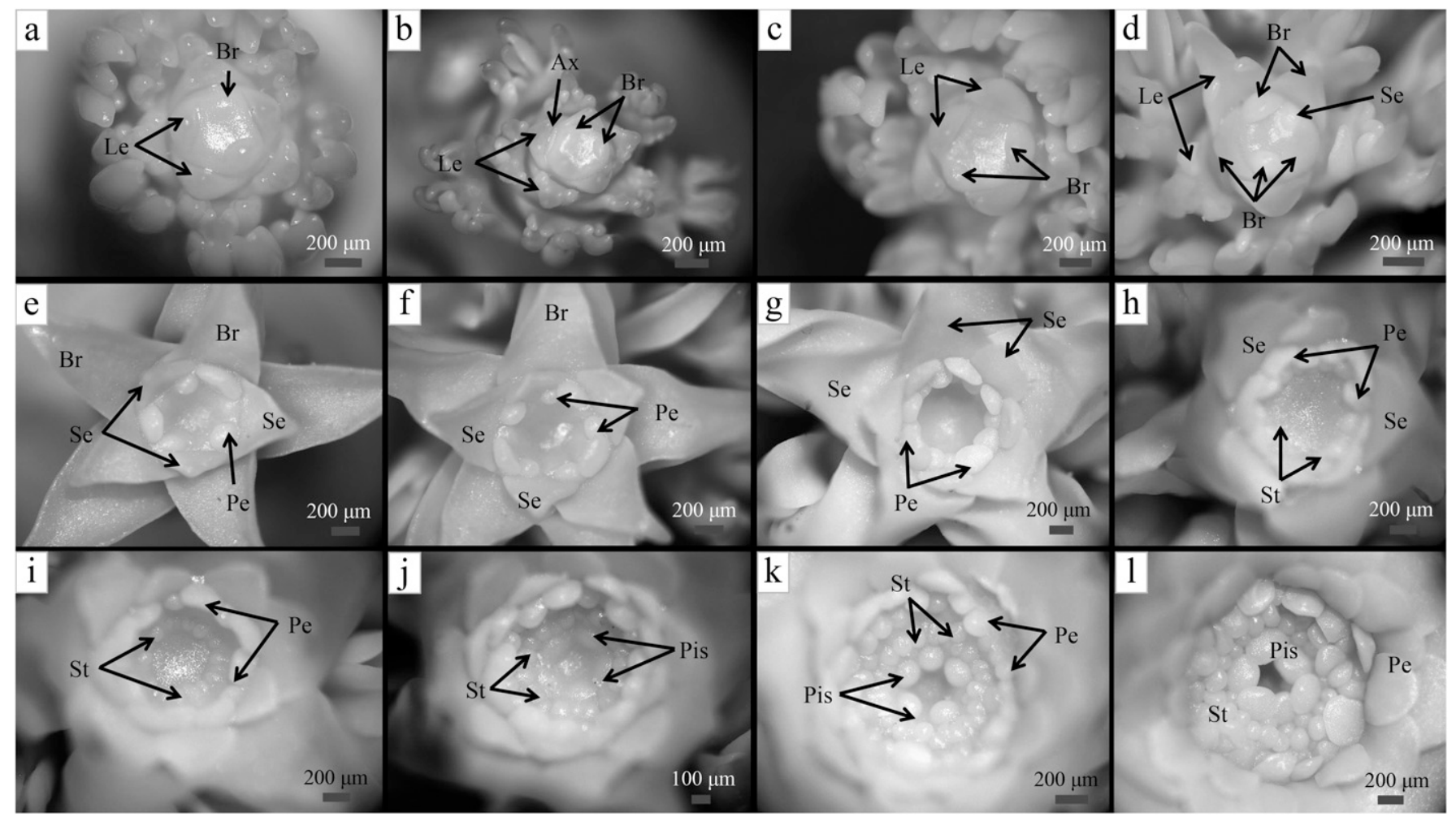

Fig. 8. Bud differentiation of the lower part of Paeonia lactiflora 'Dafugui' flower observed by stereomicroscopy. (a-c) Bract primordium differentiation period; $\mathrm{d}$ : sepal primordium differentiation period; e-g: petal primordium differentiation period; $(\mathrm{g}-\mathrm{i})$ stamen primordium differentiation period; $(\mathrm{j}-1)$ pistillode primordium differentiation period of the lower part. Pictures were taken on 26 Sept. 2016 (a-c), 1 Oct. 2016 (d), 6 Oct. 2016 (e), 11 Oct. 2016 (f), 16 Oct. 2016 (g), 21 Oct. 2016 (h-i), 27 Nov. 2016 (j), 4 Dec. 2016 (k), and 10 Mar. 2017 (l). Le: leaf primordium; Ax: axillary bud; Br: bract primordium; Se: sepal primordium; Pe: petal primordium; St: stamen primordium; Pi: pistillode primordium.

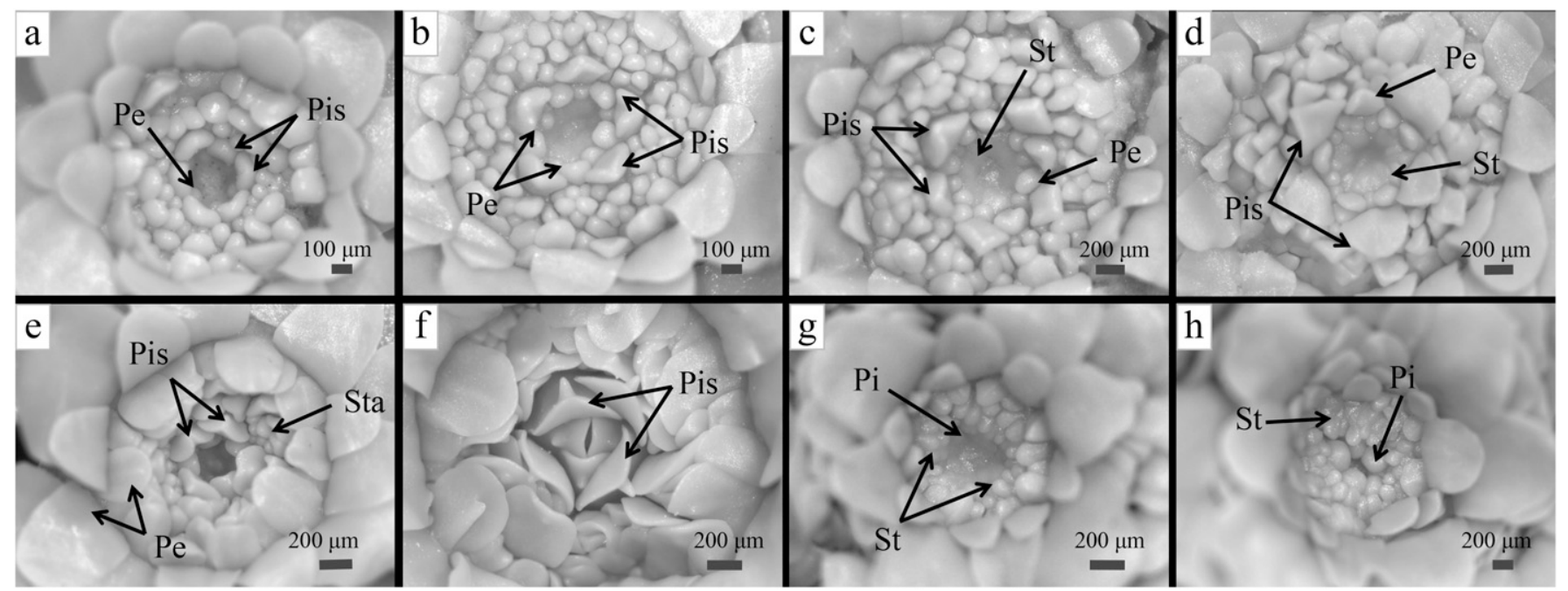

Fig. 9. Bud differentiation of the upper part of Paeonia lactiflora 'Dafugui' flower observed by stereomicroscopy. (a-b) Petal primordium differentiation period; $(\mathrm{c}-\mathrm{d})$ stamen primordium differentiation period; $(\mathrm{e}-\mathrm{f})$ staminode and pistillode development stage; $(\mathrm{g}-\mathrm{h})$ pistil primordium differentiation period. Pictures were taken on 15 Mar. 2017 (a-b), 25 Mar. 2017 (c-e), 6 Apr. 2017 (f-g), and 13 Apr. 2017 (h). Pe = petal primordium; St = stamen primordium; Sta = staminode; $\mathrm{Pi}=$ pistil primordium; $\mathrm{Pis}=$ pistillode

varies between species (Fang, 2016). Remarkably, the bud differentiation of some varieties of doubled flowers is different from the general pattern described previously. In the fall of the first year, buds proceed to the differentiation of the lower flower only while upper bud primordia initiate and complete their differentiation in the second year, in early March to April. These characters are different from other species. Generally, bud differentiation of most ornamental geophytes that bloom in spring and summer in the northern hemisphere takes place continuously after initiation of the flower bud. This is similar to Tulipa gesneriana and Narcissus tazetta var. chinensis in which flower bud differentiation is completed in one or two seasons after flowering
(Fang, 2017; Wang et al., 2011). Moreover, the developmental cycle of the flower bud of doubleflowered varieties of Nelumbo nucifera (Jiang et al., 2009), Osmanthus fragrans (Zhu et al., 2012), and tree peony (He et al., 2014) also share the same characteristics.

Although there are great differences in the development of underground buds in a wide 
Table 1. Sequence of events during the differentiation and development of Paeonia lactiflora 'Dafugui' flower buds between 2016 and 2017.

\begin{tabular}{|c|c|}
\hline Bud/flower development stage & Date \\
\hline Leaf primordium differentiation period & From mid-July 2016 to late Sept. 2016 \\
\hline Bract primordium differentiation period of the lower flower & End of Sept. 2016 \\
\hline Sepal primordium differentiation period of the lower flower & Beginning of Oct. 2016 \\
\hline Petal primordium differentiation period of the lower flower & From early to mid-Oct. 2016 \\
\hline Stamen primordium differentiation period of the lower flower & From late Oct. 2016 to mid-Nov. 2016 \\
\hline Pistillode primordium differentiation period of the lower flower & From mid-Nov. 2016 to late Nov. 2016 \\
\hline Dormant period & From end of Nov. 2016 to beginning of Mar. 2017 \\
\hline Petal primordium differentiation period of the upper flower & From early to mid-Mar. 2017 \\
\hline Stamen primordium differentiation period of the upper flower & From end of Mar. 2017 to beginning of Apr. 2017 \\
\hline Pistil primordium differentiation period of the upper flower & From early to mid-Apr. 2017 \\
\hline Flowering period & From mid to late May 2017 \\
\hline
\end{tabular}

The plants used for sampling were planted in the research field of the Germplasm Resources Nursery of the National Engineering Research Center for Floriculture $\left(116^{\circ} 39^{\prime} \mathrm{E}, 40^{\circ} 17^{\prime} \mathrm{N}\right.$; Beijing, China).

range of geographic regions and varieties, they all enter the reproductive stage from the end of August to September, and the development of a flower stalk and well-formed flowers is completed in the second spring, indicating that a "warm-cold-warm" sequence is necessary to complete their annual life cycle, which shows a similar pattern with most other geophytes; however, the effect of temperature in the life cycle of each plant species varies. Generally, relatively higher temperatures $\left(9\right.$ to $25^{\circ} \mathrm{C}$ ) are needed for most geophytes in which flower induction and early floral organogenesis take place during summer, such as Crocus, Hyacinthus, Tulipa, and Iris (Chang et al., 2008; Wang et al., 2011; Xiong, 2007; Zhang et al., 2017a). In contrast, when low temperatures $\left(4\right.$ to $\left.9{ }^{\circ} \mathrm{C}\right)$ are experienced in summer, this leads to the formation of a vegetative meristem (Kamenetsky and Okubo, 2012; Khodorova and BoitelConti, 2013). Our results show that flower bud differentiation of the lower part of $P$. lactiflora 'Dafugui' begins in late September, indicating that flower initiation and floral organogenesis are supported by relatively higher temperature in early autumn, because in this period the average minimum temperature is $9{ }^{\circ} \mathrm{C}$ and the maximum average temperature is $26^{\circ} \mathrm{C}$.

However, bud initiation and bud differentiation of the upper part begin in early March, which is similar to Allium fistulosum and Lilium pumilum, in which only low temperatures promote flower induction, and flower initiation occurs in spring (Kamenetsky and Rabinowitch, 2002; Khodorova and BoitelConti, 2013), indicating that there are differences in the mechanisms underlying physiological and genetic regulation between the lower and upper parts. Ai (2016) found that bud differentiation progressed until shoot formation in a greenhouse without cold treatment, and there were no significant differences with the differentiation process of plants in the field; however, that number of branches, flowering rate, and flower diameter were significantly reduced compared with the control group in cold storage (10 weeks at $2{ }^{\circ} \mathrm{C}$ ), and even no formation of the upper flower structure in the double type. This indicates that the optimum temperature requirement of stem elongation is different from flower bud differentiation of the lower part, but might be similar to the upper part, although this needs to be investigated further for a wider range of cultivars. The autumnwinter cooling period plays an extremely important role in controlling proper growth and flower maturation of the upper part. Usually, insufficient chilling treatment leads to slow shoot growth and flowering disorders (Fulton et al., 2001; Guo et al., 2016; Kamenetsky et al., 2003; Zhang et al., 2017b), similar to Tulipa gesneriana, Allium fistulosum, and some Iris species (Khodorova and Boitel-Conti, 2013). However, geophytes must be physiologically capable of perceiving cold treatment, which implies that low temperatures may be sensed by the meristem only after the bud reaches a certain stage of development (Barzilay et al., 2002; Le Nard and De Hertogh, 1993).

It is believed that only when the apical meristem of Tulipa bulbs has reached a stage in which all floral organs have differentiated can it be physiologically responsive to chilling treatment (Le Nard and De Hertogh, 1993). Kim et al. (1996) observed the development of $P$. lactiflora 'Taebaek' floral buds under natural conditions in South Korea, and showed that they differentiated continually in September until shoot formation in early spring. They also found that the number of days to shoot induction in a greenhouse decreased significantly by delaying forcing time from early to late December. Park et al. (2015) found that more than $85 \%$ of flower buds aborted when rootstocks were chilled at $0{ }^{\circ} \mathrm{C}$ for 8 weeks before mid-September. Zhou (2012) studied the effects of different temperature regimes on 'Dafugui', and found that buds proceeded to the petal differentiation stage only when rootstocks were chilled at $0{ }^{\circ} \mathrm{C}$ for 4 weeks, thereby promoting flowering without flower bud abortion. Thus, the flower bud differentiation stage of peony has to be taken into consideration for the development of an effective system for peony cultivation in forcing conditions (Barzilay et al., 2002). In fact, it is more important for peony growers and researchers to know when buds can sense low temperatures and when the cooling requirement is enough for stem germination and flower maturation than when the buds enter dormancy. It is generally believed that the buds of $P$. lactiflora enter endodormancy when they develop to a state when they can sense low temperatures. In fact, there was not an obvious state of dormancy for peony during this period, and the differentiation of $P$. lactiflora flower buds continues at an appropriate temperature. However, chilling is required for flower maturation and stem elongation, which is similar to endodormancy in other geophytes (Dole, 2003; Fulton et al., 2001; Zhang et al., 2017b).

The optimum temperature and duration of cold treatment of peony varieties also varies. Kamenetsky et al. (2003) suggested that the best treatment to release dormancy of $P$. lactiflora 'Sarah Bernhardt' was $2{ }^{\circ} \mathrm{C}$ for $60 \mathrm{~d}$ or $6{ }^{\circ} \mathrm{C}$ for $70 \mathrm{~d}$. Rhie et al. (2012) found that chilling for 6 weeks at 0 and 9 weeks at $5{ }^{\circ} \mathrm{C}$ was needed to break dormancy and to induce flowering in P. lactiflora 'Taebaek' and 'Mulsurae', respectively. Thus, the effectiveness of temperatures must be determined for the regulation of flowering for annual commercial production (Dole, 2003; Park et al., 2015).

The results of this study and previous studies suggest that temperature is the primary determinant of bud development in peony. Variation in this process is regulated by different temperatures that underlie the mechanism of genetic regulation of flower bud induction and differentiation between upper and lower flowers, as well as by the relationship and difference in physiological and molecular aspects. Such aspects between flower bud differentiation and stem elongation may be influenced by cold temperature and need to be investigated further.

Although several studies have been conducted on peony flower bud differentiation in the past (Table 2), their results differ considerably, especially for the bud differentiation of varieties with a double flower. Wang and Zhang (1991) used stereomicroscopy to observe flower bud differentiation of 'Dafugui', showing that it consisted of periods of differentiation of bract, sepal, petal, stamen, and pistil primordia. In our study, we found that the petal and stamen primordia differentiated twice, once for the lower part and once for the upper part. Moreover, our results of flower bud differentiation were consistent with the analysis of floral structure and morphology. Although both our study and that by Wang and Zhang (1991) used stereomicroscopy, the processes differed. In their study, the primordia of FAA-prefixed bud samples were peeled off under a stereomicroscope with microtweezers, which may damage the 


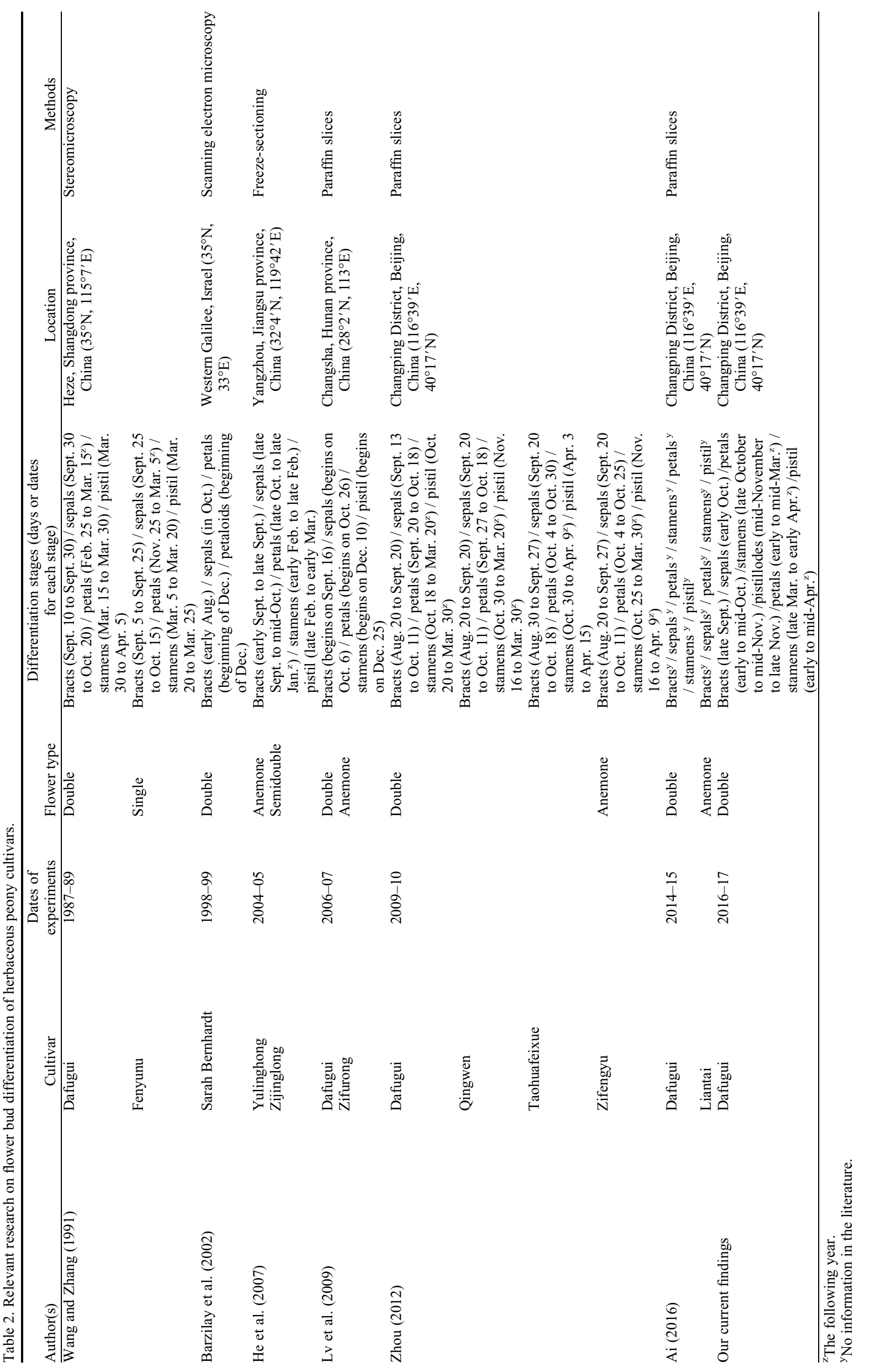

HortScience Vol. 54(1) January 2019 


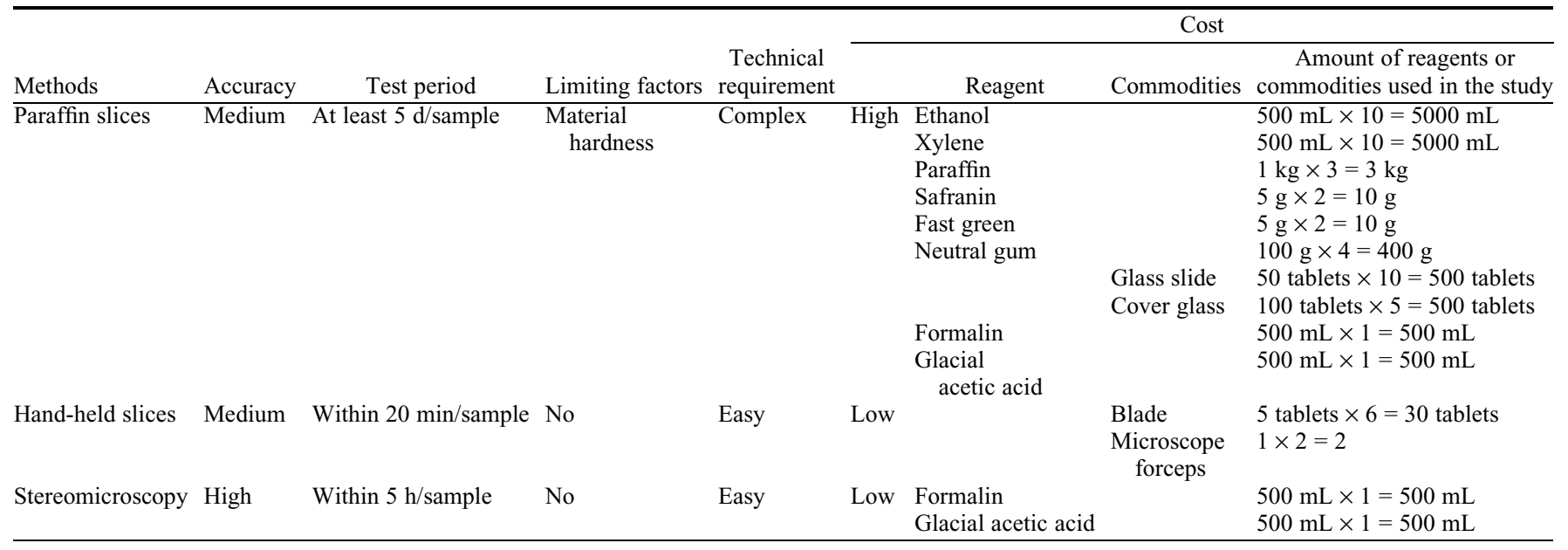

arrangement of bud primordia. This method is inconvenient to compare and analyze the morphological characteristics of different developmental stages. Lv et al. (2009) and Zhou (2012) studied the differentiation of 'Dafugui' flower buds by paraffin sections, but they did not observe the differentiation of petal, stamen, and pistil primordia of the upper flower, and often considered the pistil primordia of the upper flower as the pistillode primordia of the lower part. Careful comparison and analysis of the images of their results indicate that no bud differentiation of the upper flower was described, most likely as a result of the long sampling intervals and the researchers' subjective judgment (Barzilay et al., 2002; Lv et al., 2009; Zhou, 2012). As can be seen from the findings described previously, our stereomicroscopy-based results showed that four to five pistillode primordia were produced almost simultaneously, the morphological characteristics of pistillode primordia are similar to those of pistil primordia during their early development, only when pistillode primordia have developed to a certain size can they be identified, which is an important feature that distinguishes them from other primordia, and their morphological characteristics and developmental processes were also obviously different from normal petals, bracts, and sepals when observed by hand-held slices. In fact, from the results of our study, the pistillode primordia of the lower flower formed nearly 4 months earlier than the pistil primordia of the upper flower. Ai (2016), who investigated floral bud differentiation of 'Dafugui' by paraffin sections, showed that the process is divided into differentiation of lower and upper parts; however, the pistillode primordia of the lower flower were considered as the petal primordia of the upper part. Moreover, Ai's (2016) description of the differentiation of the upper flower was vague, and there was no information about the developmental stage of each primordium. Our results show that there are two rapid differentiation processes before and after overwintering, corresponding to early October to early November in 2016 and from mid-
March to mid-April in 2017, respectively. Thus, the time needed for the flower primordia to complete differentiation before the next developmental stage can begin is also different, indicating that a shorter sampling interval (every 5-7 d or more frequently) during these two periods are very important to accurately understand flower bud differentiation. A longer sampling interval might lead to misjudgment of some differentiation stages or create a gap in knowledge related to any stage. Naturally, the differentiation process of flower buds of other varieties of this flower type also need to be studied in different regions.

Our results show that all three methods can be used to observe flower bud differentiation of $P$. lactiflora. However, a comparison of the three observation methods of flower bud differentiation (Table 3 ) indicates that the paraffin section method is complex, and includes a series of complex or overly detailed steps, such as fixation, dehydration, wax impregnation, embedding, slicing and dyeing (i.e., it has strict methodological requirements). The entire microscopic observation takes $\approx 1$ week and requires chemical reagents, such as paraffin, xylene, and others, raising the cost (Table 3 ). However, the cellular structure of the meristem can be clearly observed by using this method. The hand-held slicing method is simple and efficient, and the results can be obtained within $20 \mathrm{~min}$, no chemical reagents are needed, and the three-dimensional image of the pictures is clearer than in paraffin sections, which is suitable for rapidly and accurately testing bud differentiation in forcing culture. It is worth noting that observation of the cut tissue of the bud must be completed within half an hour or it may become oxidized and darken, turning brown or black, making it difficult to see sections clearly. The stereomicroscopic method can be used to observe the meristem structure intuitively, not only to observe its structure and morphology, but also to analyze the way in which the flower primordia are organized and the number of structures, whereas the operating steps are relatively simple and do not consume much time, which is especially suitable for the morphological study of the bud differentiation process of varieties with a complex flower structure and of varieties with flower types that have not yet been studied. These three methods have complementary strengths that can accommodate for any weaknesses that any one method alone might have. Collectively, they form an important set of methods for the morphological research of peony flower development. One or two of these methods can be selected to carry out research according to the experimental conditions and needs of the research objective.

\section{Literature Cited}

Ai, Y.-B. 2016. Study on the flora bud stage sensitive to the low temperature in Paeonia lactiflora. Beijing For. Univ., Beijing, China, MSc Diss. (in Chinese with English abstr.).

Barzilay, A., H. Zemah, R. Kamenetsky, and I. Ran. 2002. Annual life cycle and floral development of 'Sarah Bernhardt' peony in Israel. HortScience 37:300-303.

Chang, Z.-Y., J.-Z. Zhang, G.-F. Sun, and H.-Z. Liu. 2008. Morphological studies and changes of two metabolites content during floral bud differentiation period in Iris germanica cv. Lovely Again. Bull. Bot. Res. 28:741-745. (in Chinese with English abstr.).

Cheng, F.-Y., Y. Zhong, F. Long, X.-N. Yu, and R. Kamenetsky. 2009. Chinese herbaceous peonies: Cultivar selection for forcing culture and effects of chilling and gibberellin $\left(\mathrm{GA}_{3}\right)$ on plant development. Isr. J. Plant Sci. 57:357368.

Cheng, M.-L. 2008. Flower bud differentiation process and effects of exogenous $\mathrm{GA}_{3}$ on the flower bud development of Introduced Paeonia lactiflora. Hunan Agr. Univ. Changsha, China, MSc Diss. (in Chinese with English abstr.).

Dole, J.M. 2003. Research approaches for determining cold requirements for forcing and flowering of geophytes. HortScience 38:341-346.

Fan, Z.-Q., J.-Y. Li, X.-L. Li, B. Wu, J.-Y. Wang, Z.-C. Liu, and H.-F. Yin. 2015. Genome-wide transcriptome profiling provides insights into floral bud development of summer-flowering Camellia azalea. Sci. Rep. 5:9729.

Fang, Q.-E. 2016. Study on the rules of alfalfa crown bud developing into shoot and its winter hardiness in the state of dormancy. Gansu Agr. Univ., Lanzhou, China, PhD Diss. (in Chinese with English abstr.). 
Fang, Z. 2017. Morphological study on flower bud differentiation of Narcissus tazetta var. Chinensis. Fujian Agr. and For. Univ., Fuzhou, China, MSc Diss. (in Chinese with English abstr.).

Fulton, T.A., A.J. Hall, and J.L. Catley. 2001. Chilling requirements of Paeonia cultivars. Scientia Hort. 89:237-248.

Ge, J.-T., D.-Q. Zhao, C.-X. Han, J. Wang, Z.-J. Hao, and J. Tao. 2014. Cloning and expression of floral organ development-related genes in herbaceous peony (Paeonia lactiflora Pall.). Mol. Biol. Rep. 41:6493-6503.

Guo, X., X. Hu, Y. Ma, J. Guo, Y. Ma, and Z. Zhang. 2016. Identification of differentially expressed genes during bud dormancy release in Paeonia lactiflora 'Dafugui'. Acta Hort. 1171:163-174.

Hall, A.J., J.L. Catley, and E.F. Walton. 2007. The effect of forcing temperature on peony shoot and flower development. Scientia Hort. 113:188-195.

He, D., X.-F. Gao, B.-Y. Lv, X.-L. Wang, and S.-L. He. 2014. Morphology research of flower bud differentiation of tree peony and herbaceous peony. J. Henan Agr. Sci. 43:117-120, 124. (in Chinese with English abstr.).

He, X.-D, Y.-B. Zhang, J. Wang, Y.-P. Ling, L. Yao, and J. Li. 2007. Anatomic observation of floral bud of Paeonia lactiflora. J. Anhui Agric. Sci. 35:719-720, 722 (in Chinese with English abstr.).

Huang, F.-L., H.-Y. Niu, F.-J. Meng, G.-B. Xue, B.-Z. Hu, and Y.-C. Bai. 2009. Micro-study on flower bud differentiation of Paeonia lactiflora Pall. J. Northeast Agr. Univ. 40:57-61. (in Chinese with English abstr.).

Jiang, L., F.-D. Chen, and N.-J. Teng. 2009. Comparison of flower anatomical structure of double flower and proliferation flower cultivars in Nelumbo nucifera during flower bud differentiation processes. Acta Hort. Sin. 36:12331238. (in Chinese with English abstr.).

Kamenetsky, R. and J. Dole. 2012. Herbaceous peony (Paeonia): Genetics, physiology and cut flower production. Floric. Ornam. Biotechnol. 6:62-77.

Kamenetsky, R. and H. Okubo. 2012. Ornamental geophytes: from basic science to sustainable production. CRC Press, Boca Raton, FL.

Kamenetsky, R. and H. D. Rabinowitch. 2002. Florogenesis, p. 31-57. In: H.D. Rabinowitch and L. Currah (eds.). Allium crop science: recent advances. CABI, Wallinford, UK.

Kamenetsky, R., A. Barzilay, A. Erez, and A.H. Halevy. 2003. Temperature requirements for floral development of herbaceous peony cv. 'Sarah Bernhardt'. Scientia Hort. 97:309-320.

Khodorova, N.V. and M. Boitel-Conti. 2013. The role of temperature in the growth and flowering of geophytes. Plants 2:699-711.
Kim, H.T., Y.J. Park, J.D. Seong, H.S. Suh, and S.J. Hahn. 1996. Forcing of herbaceous peony (Paeonia lactiflora PALLAS.). Hanguk Yakyong Changmul Hakhoe Chi 4:187-192.

Koutinas, N., G. Pepelyankov, and V. Lichev. 2010. Flower induction and flower bud development in apple and sweet cherry. Biotechnol. Biotec. Eq. 24:1549-1558.

Le Nard, M. and A.A. De Hertogh. 1993. Tulipa, p. 617-682. In: A. De Hertogh and M. Le Nard (eds.). The physiology of flower bulbs. Elsevier Science Publishers, Amsterdam.

Lian, Y.-S., M.-G. Zhao, Y.-P. Che, L.-Z. An, and D.-Z. Chen. 2004. The origin of the higherflower of the proliferation flower in Paeonia suffruticosa and P. lactiflora. J. Lanzhou Univ. (Nat. Sci.) 40:72-77. (in Chinese with English abstr.).

Lv, C.-P., M.-L. Cheng, N.-J. Mo, D. Ding, C.-T. Cheng, and G.-K. Wang. 2009. Effects of exogenous $\mathrm{GA}_{3}$ on flower bud development of peony. Crop Res. 23:133-135, 137, 161. (in Chinese with English abstr.).

Meyerowitz, E.M., D.R. Smyth, and J.L. Bowman. 1989. Abnormal flowers and pattern formation in floral development. Development 106:209-217.

Park, J.H., Y.H. Rhie, S.Y. Lee, and K.S. Kim. 2015. Pre-chilling promotes flowering in Paeonia lactiflora 'Taebaek' without flower bud abortion. Hort. Environ. Biote. 56:1-8.

Qin, K.-J. 2004. Herbaceous peony. China For. Publ. House, Beijing, China. (in Chinese).

Qin, K.-J. and J.-J. Li. 1990. Studies on the flower type classification of tree peony and peony cultivars. J. Beijing For. Univ. 12:18-26. (in Chinese with English abstr.).

Rhie, Y.H., H.H. Jung, and K.S. Kim. 2012. Chilling requirement for breaking dormancy and flowering in Paeonia lactiflora 'Taebaek' and 'Mulsurae'. Hort. Environ. Biotechnol. 53:277-282.

Rohde, A. and R.P. Bhalerao. 2007. Plant dormancy in the perennial context. Trends Plant Sci. 12:217-223.

Walton, E.-F., G.-F. McLaren, and H.-L. Boldingh. 2007. Seasonal patterns of starch and sugar accumulation in herbaceous peony (Paeonia lactiflora Pall.). J. Hort. Sci. Biotechnol. 82:365-370.

Wang, X.-Q., Y.-L. Zhang, L.-X. Niu, R.-F. Wang, Y.-T. Liu, and Y.-J. Cui. 2011. Morphological observation on flower bud differentiation of tulip bulb in Yangling region of Shanxi. Acta Agr. Boreali-Occidentalis Sin. 20:156-159. (in Chinese with English abstr.).

Wang, Y. and Q.-X. Zhang. 2010. New variety breeding and variation of the proliferation flower of peach-blossom. Hunan Agr. Sci.
40:110-112. (in Chinese with English abstr.).

Wang, Z.-Z. and Y.-X. Zhang. 1991. A discussion on the formation and evolution of flower type of tree peony and herb peony by observing flower bud differentiation of herbaceous peony. Acta Hort. Sin. 18:163-168. (in Chinese with English abstr.).

Xiong, Y. 2007. Study on cultivation and flower control of hyacinth. Shanghai Jiao Tong Univ., Shanghai, China, MSc Diss. (in Chinese with English abstr.).

Zhang, H.-F., Q.-C. Wei, and H.-C. Zhang. 2017a. Contents of microscopic structure, nucleic acid and soluble protein during flower bud differentiation in Crocus sativus. J. Northeast For. Univ. 45:33-36. (in Chinese with English abstr.).

Zhang, J.-P., Y. Wu, D.-Q. Li, G.-Q. Wang, X. Li, and Y.-P. Xia. 2015. Transcriptomic analysis of the underground renewal buds during dormancy transition and release in 'Hangbaishao' peony (Paeonia lactiflora). PLoS One 10: e0119118.

Zhang, J.-P., D.-Q. Li, X.-H. Shi, D. Zhang, S. Qiu, J.-F. Wei, J. Zhang, J.-H. Zhou, K.-Y. Zhu, and Y.-P. Xia. 2017b. Mining and expression analysis of candidate genes involved in regulating the chilling requirement fulfillment of Paeonia lactiflora 'Hang Baishao'. BMC Plant Biol. 17:262.

Zhang, J.-R. 2006. RAPD analysis on the germplasm resources of Camellia cultivars. Sichuan Agricultural Univ., Ya'an, China, MSc Diss. (in Chinese with English abstr.).

Zhao, D.-Q., Z.-J. Hao, and J. Tao. 2012. Effects of shade on plant growth and flower quality in the herbaceous peony (Paeonia lactiflora Pall.). Plant Physiol. Biochem. 61:187-196.

Zhao, D.-Q., Y. Jiang, C.-L. Ning, J.-S. Meng, S.-S. Lin, W. Ding, and J. Tao. 2014. Transcriptome sequencing of a chimaera reveals coordinated expression of anthocyanin biosynthetic genes mediating yellow formation in herbaceous peony (Paeonia lactiflora Pall.). BMC Genomics 15:689.

Zhou, Y.-L. 2012. Floral development and chilling requirement of Paeonia lactiflora cultivars. Beijing For. Univ., Beijing, China, MSc Diss. (in Chinese with English abstr.).

Zhu, Q., M.-F. Dong, W.-J. Yuan, B.-J. Sun, and F.-D. Shang. 2012. Studies on flower bud differentiation and leaf-like proliferate-flower bud of Osmanthus fragrans 'Tianxiang Taige'. Acta Hort. Sin. 39:315-322. (in Chinese with English abstr.). 